\title{
He. \\ Physical Performance of Anemic Adult Females, Udaipur City
}

\author{
Monica Dungarwal and Shashi Jain
}

See end of the paper for authors' affiliation

Correspondence to :

Monica Dungarwal

Home Science, Govt. Meera Girls College, Udaipur (Rajasthan) India

\section{KEY WORDS :}

Physical fitness, Anemia, Adult female
ABSTRACT : The organ and tissues of human body need a steady supply of oxygen to maintain healthy life. An adequate level of work capacity and physical fitness are important not only from point of view of well being but also of economic productivity, which especially applies to the developing countries. The present study was conducted to find out the physical performance of selected adult females. A baseline survey was conducted on 300 college adult females aged 18-25 years of Udaipur to identify 30 anemic and 10 normal females. The normal group was considered as reference group. An interview schedule was developed to collect the information about the subject and their family. The nutritional status was assessed by anthropometric measurements, Clinical and biochemical examination using standardized techniques. A group of 30 subjects was identified on the basis of hemoglobin level (Below 12g/dl) and clinical signs of anemia. Further a group of 10 normal subjects was also selected on the basis of BMI, hemoglobin and clinical examination. Haematological examination and physical performance of each selected females were assessed. The result revealed that majority of the families i.e. 74 per cent were Hindu. Eighty nine per cent were vegetarian and about 67 per cent of the families were nuclear. The percentage distribution of families as per their socio-economic status revealed that they were from middle class. The anthropometric measurements of 300 females revealed that weight and height were 80.48 and 94.86 per cent of NCHS standard for 18 years old girls, respectively. Mean BMI $\left(\mathrm{kg} / \mathrm{m}^{2}\right)$ and weight for height $(\%)$ of these females was 18.86 and 103.66 revealing that study group had normal weight for their height. Mean hemoglobin level of adult females was $10.4 \mathrm{~g} / \mathrm{dl}$. Only 27.67 per cent females were normal by hemoglobin level. Clinical signs of anemia were not common among these females indicating subclinical stage of anemia was present. Reference group had better nutritional status in comparison to anemic group with respect to all measured parameters. It was observed that reference group subjects were in superior oxidative category with 99.76 per cent physical fitness. Mean physical fitness and endurance capacity of anemic group was 77.37 per cent and 256.23 steps, respectively. These results clearly depicts that iron deficiency had negative impact on iron status and which in turn on physical performance and work capacity.

How to cite this paper : Dungarwal, Monica and Jain, Shashi (2018). Physical Performance of Anemic Adult Females, Udaipur City. Internat. J. Med. Sci., 11(1\&2) : 13-20, DOI: 10.15740/HAS/IJMS/11.1and2/1320.Copyright@2018: Hind Agri-Horticultural Society.
Paper History :

Received : 23.11 .2017

Revised : 14.09.2018;

Accepted : 25.09.2018 